\title{
Clinical Study of Obesity and associated morbidities in patients admitted to College of Medical Sciences Teaching-Hospital, Bharatpur
}

\section{Manohar Pradhan}

Department of General Practice and Emergency Medicine, College of Medical Sciences, Bharatpur, Nepal

\author{
Correspondence \\ Dr. Manohar Pradhan, \\ Dept of General Practice and \\ Emergency Medicine, \\ College of Medical Sciences-TH, \\ Bharatpur, Nepal \\ Email: \\ manoharpradhan@hotmail.com
}

DOI:

http://dx.doi.org/10.3126/

jcmsn.v11i3.14058

\begin{abstract}
Background and Objectives: The present study was conducted with objective to study the incidence of obesity and associated co-morbidities in patients admitted to CMS-TH, Bharatpur. Materials and Methods: One hundred and fifty consecutive overweight patients from the January 2009 to December 2012 with Basal metabolic index $(\mathrm{BMI})>25$ and obese patients (BMI $>30)$ were included in this hospital based prospective study. Detailed evaluation of risk factors and family history of other diseases were taken, other obesity related indicators like WPRO, 2000 for BMI, waist circumference (NCEP ATP III and NCEP for South Asian ethnicity) NCEP - National Cholesterol Education Program and waist hip ratio (WHO criteria) were measured and comparison done in order to detect best method for application. These cases were evaluated for associated comorbid condition and metabolic syndrome which were diagnosed using NCEP ATP III criteria. Results: The mean age of patients was 52.7 years. Commonest co-existing risk factors were alcohol consumption, smoking, hypertension and type 2 diabetes mellitus. Evaluation based on WHO criteria revealed that $56.7 \%$ patients were overweight, $38.7 \%$ were obese class II and $4.6 \%$ were class II. While $45.1 \%$ male and $69.1 \%$ female patients had central obesity. The figure was $81.7 \%$ for males and $94.1 \%$ for females with WHO criteria using waist hip ratio. Risk factors like alcohol consumption $(52.7 \%)$, smoking $(52.7 \%)$ and fatty liver disease (22.66\%) were the commonest co-morbid conditions. Conclusion: In the present study, risk factors of alcohol, smoking and hypertension and comorbid conditions diabetes mellitus, dyslipidemia, ischemic heart disease, stroke and fatty liver were noted. Waist hip ratio was the best indicator to detect central obesity and co-morbid conditions and recommended to be used for Nepali population.

Key words: Body Mass Index; dyslipidemia; obesity; risk factors; type II diabetes mellitus
\end{abstract}

Citation: Pradhan M. Clinical Study of Obesity and associated morbidities in patients admitted to College of Medical Sciences Teaching-Hospital, Bharatpur. JCMS Nepal. 2015;11(3):16-19.

\section{INTRODUCTION}

Obesity is a chronic non-communicable disease, characterized by deposition of fat and adipose tissue resulting from the discrepancy between energy consumption and expenditure. The morbidity \& mortality attributable to obesity was expected to increase to $57 \%$ by 2020 . Almost half of the deaths are attributable to cardiovascular disease and Diabetes Mellitus. The global nature of obesity was formally recognized by WHO consultation in 1997. ${ }^{1}$
A high incidence of obesity was reported from developed countries including USA where $65 \%$ of adult population were overweight and in addition another $30 \%$ were obese. ${ }^{2}$ The longitudinal and cross section data analysis in intermediate developed countries also revealed an increase in incidence of obesity from $30 \%$ to $100 \%$ over the past decade. Obesity is now considered as an epidemic disease of $21^{\text {st }}$ century. ${ }^{3}$

Obesity is associated with increased risk factors for all systems in the human body. ${ }^{4}$ Epidemiological 
studies suggest that all causes, metabolic, malignancies and CVD morbidities begin to rise when BMI is $>25,{ }^{5-7}$ especially associated with HTN and type II DM. ${ }^{8}$ The complication of obesity is strongly linked to intra-abdominal adiposity 9,10 . Visceral abdominal obesity confirms more risk than subcutaneous abdominal obesity ${ }^{11}$.

New criteria for Asian ethnic specific value WPRO 2000 (Western Pacific Region of WHO criteria pertaining to obesity) ${ }^{12}$ uses lower $\mathrm{BMI}>23 \mathrm{~kg} / \mathrm{m}^{2}$. Abdominal obesity is defined by National Cholesterol Education Programme- Adult Treatment Panel III (NCEP-ATPIII) ${ }^{13}$ using waist circumference standard for American male $>90 \mathrm{~cm}$ and female $>88 \mathrm{~cm}$, and for South Asian male $>90$ $\mathrm{cm}$ and female $>80 \mathrm{~cm}$.

WHO uses Waist Hip ratio ${ }^{1}>0.90$ for male \& $>0.85$ for female. Studies are lacking in Nepalese population ${ }^{1}$.

\section{MATERIALS AND METHODS}

This cross sectional study was conducted in the CMS-TH, Bharatpur from January 2009 to December 2012. One hundred fifty consecutive obese patients admitted to medical wards were enrolled in this study. A detailed history along with information regarding risk factors of obesity was taken. Past history of HTN, IHD, DM, CVA was recorded. Personal history of dietary habits, alcohol abuse, tobacco chewing, cigarette smoking was taken. Accordingly relevant investigations were done as described below. Examination for obesity: height (centimeter), weight (kilogram), BMI, abdominal girth, waist hip measurement were done.

Table 1: Classification of BMI (WHO Classification)

\begin{tabular}{|lcl}
\hline Classification & BMI $\mathbf{k g} / \mathbf{m}^{2}$ & $\begin{array}{l}\text { Risk of } \\
\text { Morbidity }\end{array}$ \\
\hline Under wt & $<18.5$ & Low \\
\hline Normal range & $18.5-24.9$ & Average \\
\hline Over wt & $>\mathbf{2 5 . 0}$ & \\
\hline Pre-obese & $25.0-29.9$ & Mild \\
\hline Obese-class I & $30.0-34.9$ & Moderate \\
\hline Obese-class II & $35.0-39.9$ & Severe \\
\hline Obese-class III & $>40$ & Very severe \\
\hline
\end{tabular}

Table 2: Classification according to Western Pacific Region of WHO for Obesity ${ }^{12}$

\begin{tabular}{lcl} 
Classification & $\mathbf{B M I} \mathbf{~ k g} / \mathbf{m}^{\mathbf{2}}$ & Risk of Morbidity \\
\hline Under wt & $<18.5$ & Low \\
\hline Normal range & $18.5-22.9$ & Average \\
Over wt & $>\mathbf{2 3}$ & \\
\hline At Risk & $23-24.5$ & Mild \\
Obese I & $25-29.9$ & Moderate \\
Obese II & $>30$ & CBR
\end{tabular}

Measurement of central obesity: waist hip ratio ${ }^{14}$ was measured by flexible tape at the narrowest circumference between the costal margin and iliac crest, in horizontal plane. Hip circumference was measured in centimeter $\mathrm{m}$ at maximum circumference, at the level of greater trochanter in the horizontal plane over the buttocks. BMI was calculated as: $\mathrm{BMI}=$ weight $/$ height $^{2}$. Over weight was defined as BMI $>25$ and obese patients as BMI $>30$.

\section{RESULT}

Following observations were made in 150 patients. The maximum number of patients were between 40 -49 years. Female patients outnumbered the male patients. Mean age was 52.7 years; with range of 15 -65 years.

Maximum number of male patients were farmers (40 or $26.6 \%$ ) and female were housewives (50 or $33.3 \%)$. Forty nine (32.66\%) patients were illiterates, 29 patients $(19.33 \%)$ had no formal education but could write their name. Fifty two $(34.66 \%)$ patients had primary education. Thus 130 (86.6\%) patients were from low level of education. Forty eight (32\%) patients belonged to Mongolian

Table 3: Distribution of males and females with age range

\begin{tabular}{|cccc|}
\hline Age & Male & Female & Total \\
\hline$<20$ & 4 & 2 & 6 \\
\hline $20-29$ & 2 & 3 & 5 \\
$30-39$ & 10 & 6 & 16 \\
$40-49$ & 25 & 37 & 62 \\
$50-59$ & 14 & 14 & 28 \\
\hline 60 & 15 & 18 & 33 \\
\hline Total & 70 & 80 & 150 \\
\hline
\end{tabular}


Table 4: Associated risk factors for obesity

\begin{tabular}{lll} 
Co-Morbidities & $\begin{array}{l}\text { No of } \\
\text { patients }\end{array}$ & Percentage \\
\hline HTN & 81 & $54 \%$ \\
\hline DM & 40 & $23.3 \%$ \\
\hline Hypothyroidism & 10 & $6.5 \%$ \\
\hline Chronic smokers & 79 & $52.7 \%$ \\
\hline Alcoholics & 79 & $52.7 \%$ \\
\hline Dyslipidemias & 89 & $56.8 \%$ \\
\hline CVA & 36 & $8.0 \%$ \\
Fatty Liver & 44 & $22.2 \%$ \\
\hline Cholelithiasis & 10 & $5 \%$ \\
Acid Peptic Disease & 22 & $11 \%$ \\
\hline Gastro esophageal & 7 & $4.6 \%$ \\
reflux disease & & \\
\hline Respiratory & 10 & $6.5 \%$ \\
\hline IHD & 12 & $8 \%$ \\
\hline Arrhythmias & 17 & $11.3 \%$ \\
\hline Heart failure & 17 & $11.3 \%$ \\
\hline
\end{tabular}

group, 46 (30.64\%) patients were Brahmins, and 29 (19.36\%) patients were Kshetris and $27(18 \%)$ patients from other caste.

In the present prospective study, data obtained from 150 patients (both genders) having BMI more than 25 , were analyzed. Evaluation based on WHO criteria revealed that $56.7 \%$ patients were overweight, $38.7 \%$ were obese class I and $4.6 \%$ were class II. While $45.1 \%$ male and $69.1 \%$ female patients had central obesity (NCEP guidelines for South Asian population), the figure was $81.7 \%$ for males and $94.1 \%$ for females with WHO criteria using waist hip ratio. Most of the previous studies were on epidemiological basis. ${ }^{15,16}$ The associated risk factors for obesity are described in table 4 .

\section{DISCUSSION}

A sharp increase in number of obese and overweight people has been observed around the world. Similarly the prevalence of comorbid situations and its impact on health care delivery systems has also been widely studied worldwide however very few such studies have been conducted in Nepalese populations. Low income countries like Nepal, where there has been steady increase in urban population and sedentary life style and the focus is still on curative rather than prevention of disease, are likely to be hit hardest by future toll of obesity epidemic.

In this study 150 patients having BMI $>25$ in both gender were studied. The first nationally representative study was conducted in Nepal in 2007. The Nepal Non-Communicable Diseases Risk Factor Survey, which included 15 of 75 districts and represented all five administrative regions and three ecological regions, estimated the prevalence of overweight (BMI: 25-30) at about 7\% and the prevalence of obesity $(\mathrm{BMI}<30)$ at around $1.7 \%$ Based on the WHO-STEPS manual, this WHO-funded NCD risk factor survey began in 2003 as a pilot study in Kathmandu. It was extended to three other districts in 2005 and became a national survey in 2007. Similarly another study estimates the prevalence of obese adults in Nepal to be $2.9 \%$. Other regional studies conducted since 2000 have shown a prevalence of overweight (between $20 \%$ and $34 \%$ ), but prevalence of obesity varied widely $(0.4 \%$ to $10.14 \%)$. In our study differing methodologies, sample sizes, and varying study population probably explain these variations compared to relevant national prevalence rates. The age of the patients in the, study group ranged from 15 yrs to 65 yrs with mean age of 52.7 yrs the number of males $68(45.3 \%) \&$ females $82(54.7 \%)$ which indicates higher incidence of obesity in female patients which is similar to as reported in previous studies. This variation based on sex requires further studies but it may be due to sedentary life style of the female population (mostly housewives) as compared to males. More than one co-morbid risk factors were commonly noted. The most important co-existent risk factors are smoking (79:52.7\%) alcohol abuse (79:52.7 \%), HTN (89:54.3\%) \& type II DM (32:21.8\%) as per American Diabetic Association criteria ${ }^{17}$. Heart diseases were seen in 27(18\%) \& arrhythmias in 17 $(11.3 \%)$. These findings are similar to previous studies which have proved that both overweight and obesity are associated with the incidence of multiple co-morbidities including type II diabetes, cancer and cardiovascular diseases

New criteria for Asian ethnic specific value WPRO 2000 (Western Pacific Region of WHO criteria pertaining to obesity, ${ }^{12}$ uses lower BMI $>23 \mathrm{~kg} / \mathrm{m}^{2}$. Abdominal obesity is defined by National Cholesterol Education Programme- Adult Treatment Panel III (NCEP-ATPIII) ${ }^{13}$ using waist circumference standard for American male $>90 \mathrm{~cm}$ 
$\&$ female $>88 \mathrm{~cm}$, and for south Asian male $>90$ $\mathrm{cm}$, and female $>80 \mathrm{~cm}$. WHO uses Waist Hip ratio ${ }^{1}>0.90$ for male and $>0.85$ for female. Studies are lacking in Nepalese population. ${ }^{1}$

\section{CONCLUSION}

The hospital based clinical study of obesity and comorbidities in 150 patients admitted to CMS-TH whose BMI was $>25$ as per WHO criteria. Patients with central obesity had significantly higher risk of co-morbidities $94 \%$ in females and $81 \%$ male Incidence of obesity was common in females $(54.67$ $\%)$ when compared to males $(45.33 \%)$. Waist hip ratio was the best indicator to detect central obesity \& recommended to be used for Nepali population. The most important risk factors were smoking, alcohol and hypertension.

\section{REFERENCES}

1. WHO obesity: preventing \& managing the global epidemic. In report of a WHO consultation (2000) Geneva.

Switzerland (WHO technical report series 894).

2. Hedley AA, Ogden CL, Johnson CL, Carroll MD, Curtin LR, Flegal KM. Prevalence of over weight and obesity among USA children, adolescents \& adults, 1999-2000. JAMA. 2004;291(23):2847-50.

3. Popkin BM. The nutrition transition: an overview of world patterns of change. Nutr Rev. 2004;62:140-3.

4. James WPT. Epidemiology of obesity. In: Chadwick DJ. Cardew G C (editions). The origin \& consequences of obesity. Chichester, Wiley: Ciba foundation symposium. 1996;201:1-16. PMCId:1380516.

5. Hubert HB. Obesity as an independent risk factor for CVD: 26 yrs follow up of participants in the Framingham Heart study. Circulation 1983; 67:968-77. DOI: 10.1161/01.CIR.67.5.968; PMID:6219830.

6. Manson JE. A prospective study of obesity \& risk of CHD in woman. NEJM 1990; 322:882-9. DOI: 10.1056/ NEJM199003293221303; PMID:2314422.

7. Han TS, Van Leer EM, Seidell JC, Lean ME. Waist circumference action levels in the identification of cardiovascular risk factors: prevalence study in a random sample. BMJ. 1995;311:1401-5. DOI: 10.1136/ bmj.311.7017.1401; PMID: 8520275.

8. Flier JS, Flier EM, Braunwald E (Eds).Biology of obesity. Harrison's Principles Int. Med. 2011;1:18 ${ }^{\text {th }}$ Ed.

9. Jensen MD, Haymond MW, Rizza RA, Cryer PE, Miles JM. influence of body fat distribution on free fatty acid metabolism in obesity J Clin. Invest. 1989, 83:1168-73. DOI: 10.1172/JCI1 13997; PMID: 2649512.

10. Fugioka S, Matsuzawa $Y$, et al. Contribution of intra abdominal. fat accumulation to the impairment of glucose \& lipid metabolism in human obesity. Metabolism. 1987;36 (1):54-9. PMID: 3796297.
11. Vaga G.L. Obesity the Metabolic syndrome and CVD. American. Heart. J. 2001; 142: 1108-16. DOI: 10.1067/ mhj.2001.119790.

12. WHO/IASO/IOTF: The Asia pacific perspective: redefining obesity and its treatment health communication Australia Pvt Ltd: 2000.

13. Grundy SM. Report of National Heart, Lung \& Blood institute/AHA conference on scientific issue related to definition. Circulation 2004; 109:433 -8. DOI: 10.1161/01.CIR.0000112379.88385.67; PMID: 14744958.

14. Forbes GB, Reina JC. Adult lean body mass decline with age some longitudinal observation. Metabolism: clinical and experimental. 1970; 19:653-63. DOI: 10.1016/00260495(70)90062-4.

15. Nepal non-communicable disease risk factors survey 2007. Ministry of Health and Population: Kathmandu, Nepal, 2008.

16. Balarajan.villamor E. National representative surveys show recent increase in the prevalence of over weight and obesity among women of reproductive age in Bangladesh, Nepal and India. J. Nutr. 2009; 139:2139-44. DOI: 10.3945/ jn.109.112029; PMID: 19776182.

17. ADA, standards of medical care in DM-2010:1:11-61. 